\title{
Translational Research for Acute Pancreatitis - Which Results Have Really Influenced Our Therapy?
}

\author{
Jan D'Haese Jens Werner \\ Department of General, Visceral, Transplantation, Vascular and Thoracic Surgery, University of Munich, LMU, Munich, Germany
}

\section{Keywords}

Capillary blood flow - Hemodilution - Dextran . Intercellular adhesion molecule-1, ICAM - Fluid resuscitation

\section{Summary}

Acute pancreatitis is a common disease characterized by acinar cell destruction and acute inflammatory changes of the pancreas that lead to a systemic inflammatory response. A major research effort has been undertaken to unravel the underlying pathophysiology and to identify possible therapeutic targets. Still, only very few findings have influenced our clinical practice in the treatment of acute pancreatitis. Pancreatic microcirculation and capillary blood flow have long been suspected to play a major role in the course of the disease. It therefore seemed tempting to speculate that manipulation of the vasoconstrictor endothelin or its antagonist nitrogen monoxide could positively influence the outcome. We had to acknowledge, however, that these mechanisms take place very early in the disease course and that only prophylactic applications show an effect; this is useful in the setting of pancreas transplantation and endoscopic retrograde cholangiopancreatography but not applicable for clinical use in the therapy of acute pancreatitis. Research then focused on later pathophysiological stages of the disease, mainly on the process of adhesion and extravasation of leukocytes into the pancreatic tissue. Here, integrins and adhesion molecules like the intercellular adhesion molecule-1 (ICAM-1) were investigated in detail. A monoclonal antibody to ICAM-1 showed promising results in experimental models but was never further evaluated in the clinical setting. Hemodilution and fluid resuscitation was

Data from this manuscript have in part been presented at the symposium 'Frontiers in Surgical Evolution' on September 21, 2018 in honor of Prof. Dr. Ernst Klar, Rostock, Germany. recognized to be an important therapeutic tool in acute pancreatitis. Here, initial experimental studies favored colloid solutions, and especially dextrans for isovolemic fluid resuscitation. It was recognized only later that colloid solutions are not effective and may even increase mortality in critically ill patients. Therefore, goal-directed infusion of Ringer's lactate solution at a moderate infusion rate to optimize volume status and hemoconcentration in acute pancreatitis is now advocated. In summary, out of the numerous experimental and translational studies, only very few have really influenced our daily clinical practice. Further research is therefore needed to find more specific and effective therapeutic agents for the treatment of acute pancreatitis.

(c) 2018 S. Karger GmbH, Freiburg

\section{Introduction}

Acute pancreatitis is an inflammatory condition of the pancreas which causes a local and systemic inflammatory response. While most patients develop mild disease, up to $20 \%$ develop moderate to severe pancreatitis with pancreatic necrosis and/or multi-organ failure $[1,2]$. The incidence has been rising in recent years, and especially the severe forms are a major clinical and financial health care burden [3]. The most common etiologic factors are gallstones and alcohol, followed by ischemia, hyperlipidemia, hypercalcemia, and hereditary factors. On a pathophysiological level, all these factors seem to primarily affect the acinar cell, resulting in the premature activation of trypsinogen and other digestive enzymes which consequently trigger the onset of the disease. A major research effort has been undertaken to unravel the precise mechanisms and to identify potential therapeutic targets in acute pancreatitis. Nevertheless, until today, only very few findings have made their way from bench to bedside and into routine clinical practice. This review focusses on these findings from translational research which have influenced our therapy of acute pancreatitis.

\section{KARGER}

(c) 2018 S. Karger GmbH, Freiburg
Prof. Dr. med. Jens Werner

Department of General, Visceral, Transplantation, Vascular and Thoracic Surgery University of Munich, LMU

Marchioninistraße 15, 81377 Munich, Germany

jens.werner@med.lmu.de 


\section{Pancreatic Microcirculation - Capillary Blood Flow}

Development of pancreatic edema is the first step in the pathogenesis of acute pancreatitis. In cases of mild pancreatitis, this will fully resolve over time. However, in cases of severe pancreatitis, edema will progress to peripancreatic fluid collections and pancreatic necrosis. Pancreatic microcirculation is thought to be one of the key factors that determines the course and the severity of the disease $[4,5]$. This hypothesis is based on the findings of intravital microscopy in rabbits and rats which, on the one hand, showed a homogeneously increased capillary blood flow in mild pancreatitis and, on the other hand, a persistently decreased capillary perfusion in experimental necrotizing pancreatitis [6, 7]. Reduced pancreatic microcirculation in severe pancreatitis induces hypoxia of the pancreatic tissue and consequently the inflammatory cascade and tissue necrosis. Pancreatic tissue necrosis is not homogeneous, and toxic mediators that further compromise pancreatic microcirculation are released $[3,6,8]$. Interestingly, both alcohol and cigarette smoke seem to selectively impair hemoglobin oxygen saturation in the pancreas and may thereby additionally provoke pancreatic hypoxia $[9,10]$. Furthermore, cigarette smoke potentiates the amount of pancreatic injury generated by ethanol alone and thus seems to be a relevant contributing factor to alcohol-induced acute pancreatitis [10].

Independent of etiology, reduced pancreatic microcirculation is based on vasoconstriction of the arterioles [6], higher flow resistance in postcapillary venules due to increased leukocyte-endothelium interactions $[5,11]$, arteriovenous shunts [12], and local activation of intravascular coagulation [6]. One important mechanism in the initial state of impaired microcirculation is the imbalance of endothelin and nitrogen monoxide (NO) [13]. Endothelin leads to vasoconstriction and an increased vascular permeability. Protective effects have been observed when endothelin was antagonized or NO was administered in experimental models [13]. However, these effects were only observed when treatment was given prophylactically, and no effect was observed when treatment was applied in a therapeutic approach. This finding is most likely explained by the fact that the underlying mechanisms take place in the very early phase of the disease. Therefore, inhibition of these initial processes comes too late once disease progression has started. In order to find targetable mechanisms that may allow a therapeutic intervention and therefore a possible future clinical application, leukocyteendothelium interactions seemed to be much more promising since they occur later in the course of the disease.

\section{Leukocyte-Endothelium Interactions}

After the initial impairment of capillary blood flow through vasoactive substances like endothelin and $\mathrm{NO}$, the endothelium starts to increasingly express adhesion molecules which aggravate leukocyte adhesion and extravasation [5]. Selectins account for the 'rolling', the first step in leukocyte adhesion, while integrins and the intercellular adhesion molecule-1 (ICAM-1) lead to the 'stick- ing' and extravasation of leukocytes. This overexpression of ICAM-1 is observed much later than the initial findings of acute pancreatitis such as the activation of trypsinogen and cytokines [5, 14]. Therefore, ICAM-1 seemed to be an interesting target in acute pancreatitis, and preliminary results were promising [15]. Nevertheless, further and especially clinical studies on this target are missing, and targeting of ICAM-1 has never come to a clinical application in acute pancreatitis. Up to date, numerous studies have been undertaken to influence pancreatic capillary blood flow through various targets in pancreatitis, and some have shown promising results in experimental models in rats or mice. However, none of these specific agents have ever been shown to be effective in human acute pancreatitis. Nevertheless, one important aspect that majorly influences microcirculation and which has found its way into current clinical guidelines is early goal-directed fluid resuscitation $[2,16]$.

\section{Fluid Resuscitation - Hemodilution}

It is long known that fluid resuscitation is a major clinical challenge in critically ill patients. This seems to be especially the case in acute pancreatitis patients. Inflammation of the pancreas and the corresponding systemic inflammatory response leads to the extravasation of fluid to the third space with consequent hypovolemia, hypoperfusion, and organ failure. In fact, fluid resuscitation is probably the intervention that is most likely to improve clinical outcomes [17-19]. Early experimental studies have suggested that resuscitation with colloid solutions, leading to an isovolemic hemodilution, are beneficial for pancreatic microperfusion in the setting of acute experimental pancreatitis. Various dextrans seemed to be superior to other colloid solutions [20-22], and first reports of the clinical use of dextran in severe pancreatitis were promising [23]. Only later it became clear that in critically ill patients in general, colloids should be discouraged since the evidence for their effectiveness is missing and hydroxyethyl starch may even increase mortality $[24,25]$. Therefore, the current IAP/APA guideline suggests goal-directed infusion of Ringer's lactate solution at a moderate infusion rate of $5-10 \mathrm{ml} / \mathrm{kg} / \mathrm{h}$ since higher infusion rates and rapid hemodilution to a hematocrit of $<35 \%$ in $48 \mathrm{~h}$ is associated with worse outcome [16]. Non-invasive clinical targets to measure fluid resuscitation are suggested as: i) heart rate $<120$ / min, ii) mean arterial pressure between 65 and $85 \mathrm{~mm} \mathrm{Hg}$, and iii) urinary output $0.5 \mathrm{ml} / \mathrm{kg} / \mathrm{h}$ [16]. In this sense, evidence-based fluid resuscitation has become a lot more sophisticated in the last decades.

\section{Conclusion}

Numerous studies have investigated and largely unraveled the pathophysiology of acute pancreatitis. Despite the growing understanding of the underlying mechanisms and the evaluation of multiple potential therapeutic targets, it is still sobering to recognize 
that after decades of experimental and translational studies only very few results have influenced our clinical management of acute pancreatitis. Future studies should aim to identify specific therapeutic targets in acute pancreatitis, and more effort should be made to bring these promising targets into clinical evaluation.

\section{Disclosure Statement}

Sources of funding for this publication: None.

The authors declare that they have no conflicts of interest and no ethical conflicts to disclose.

\section{References}

1 Banks PA, Freeman ML: Practice guidelines in acute pancreatitis. Am J Gastroenterol 2006;101:2379-2400.

$\checkmark 2$ Crockett SD, Wani S, Gardner TB, Falck-Ytter Y, Barkun AN: American Gastroenterological Association Institute Guideline on initial management of acute pancreatitis. Gastroenterology 2018;154:10961101.

3 Krishna SG, Kamboj AK, Hart PA, Hinton A, Conwell DL: The changing epidemiology of acute pancreatitis hospitalizations: a decade of trends and the impact of chronic pancreatitis. Pancreas 2017;46:482-488.

4 Klar E, Schratt W, Foitzik T, Buhr H, Herfarth C, Messmer K: Impact of microcirculatory flow pattern changes on the development of acute edematous and necrotizing pancreatitis in rabbit pancreas. Dig Dis Sci 1994;39:2639-2644.

5 Werner J, Dragotakes SC, Fernandez-del Castillo C, Rivera JA, Ou J, Rattner DW, Fischman AJ, Warshaw AL: Technetium-99m-labeled white blood cells: a new method to define the local and systemic role of leukocytes in acute experimental pancreatitis. Ann Surg 1998;227:86-94.

6 Klar E, Messmer K, Warshaw AL, Herfarth C: Pancreatic ischaemia in experimental acute pancreatitis: mechanism, significance and therapy. Br J Surg 1990; 77:1205-1210.

7 Schmidt J, Ebeling D, Ryschich E, Werner J, Gebhard MM, Klar E: Pancreatic capillary blood flow in an improved model of necrotizing pancreatitis in the rat. J Surg Res 2002;106:335-341.

8 Klar E, Herfarth C, Messmer K: Therapeutic effect of isovolemic hemodilution with dextran 60 on the impairment of pancreatic microcirculation in acute biliary pancreatitis. Ann Surg 1990;211:346-353.

-9 Foitzik T, Fernandez-del Castillo C, Rattner DW, Klar E, Warshaw AL: Alcohol selectively impairs oxygenation of the pancreas. Arch Surg 1995;130:357-360; discussion 361 .
10 Hartwig W, Werner J, Ryschich E, Mayer H, Schmidt J, Gebhard MM, Herfarth C, Klar E: Cigarette smoke enhances ethanol-induced pancreatic injury. Pancreas 2000;21:272-278.

11 Werner J, Schmidt J, Gebhard M, Herfarth C, Klar E: Überlegenheit von Dextran gegenüber HAES und Kristalloiden in der Hemmung der Leukocyten-Endothel-Interaktion bei experimenteller nekrotisierender Pankreatitis. Langenbecks Arch Chir Forum 1996; 24(suppl 2):467-470.

12 Klar E, Endrich B, Messmer K: Microcirculation of the pancreas. A quantitative study of physiology and changes in pancreatitis. Int J Microcirc Clin Exp 1990; 9:85-101.

13 Werner J, Rivera J, Fernandez-del Castillo C, Lewandrowski K, Adrie C, Rattner DW, Warshaw AL: Differing roles of nitric oxide in the pathogenesis of acute edematous versus necrotizing pancreatitis. Surgery 1997;121:23-30.

14 Werner J, Z'Graggen K, Fernandez-del Castillo C, Lewandrowski KB, Compton CC, Warshaw AL: Specific therapy for local and systemic complications of acute pancreatitis with monoclonal antibodies against ICAM-1. Ann Surg 1999;229:834-840; discussion 841842.

15 Werner J, Hartwig W, Schmidt E, Gebhard MM, Herfarth C, Klar E: Reduction of local and systemic complications of acute pancreatitis by monoclonal antibody to ICAM-1 (Article in German). Langenbecks Arch Chir Suppl Kongressbd 1998;115(suppl 1):725729.

16 Working Group IAP/APA Acute Pancreatitis Guidelines: IAP/APA evidence-based guidelines for the management of acute pancreatitis. Pancreatology 2013; 13(suppl 2):e1-15.
7 Gardner TB, Vege SS, Pearson RK, Chari ST: Fluid resuscitation in acute pancreatitis. Clin Gastroenterol Hepatol 2008;6:1070-1076.

18 Stigliano S, Sternby H, de Madaria E, Capurso G, Petrov MS: Early management of acute pancreatitis: a review of the best evidence. Dig Liver Dis 2017;49: 585-594.

19 van Dijk SM, Hallensleben NDL, van Santvoort HC, Fockens P, van Goor H, Bruno MJ, Besselink MG: Acute pancreatitis: recent advances through randomised trials. Gut 2017;66:2024-2032.

20 Schmidt J, Huch K, Mithofer K, Hotz HG, Sinn HP, Buhr HJ, Warshaw AL, Herfarth C, Klar E: Benefits of various dextrans after delayed therapy in necrotizing pancreatitis of the rat. Intensive Care Med 1996;22: $1207-1213$.

21 Huch K, Schmidt J, Schratt W, Sinn HP, Buhr H, Herfarth C, Klar E: Hyperoncotic dextran and systemic aprotinin in necrotizing rodent pancreatitis. Scand J Gastroenterol 1995;30:812-816.

22 Hotz HG, Schmidt J, Ryschich EW, Foitzik T, Buhr HJ, Warshaw AL, Herfarth C, Klar E: Isovolemic hemodilution with dextran prevents contrast medium induced impairment of pancreatic microcirculation in necrotizing pancreatitis of the rat. Am J Surg 1995;169:161166.

23 Klar E, Foitzik T, Buhr H, Messmer K, Herfarth C: Isovolemic hemodilution with dextran 60 as treatment of pancreatic ischemia in acute pancreatitis. Clinical practicability of an experimental concept. Ann Surg 1993;217:369-374.

24 Perner A, Haase N, Guttormsen AB, et al: Hydroxyethyl starch 130/0.42 versus Ringer's acetate in severe sepsis. N Engl J Med 2012;367:124-134.

25 Perel P, Roberts I, Ker K: Colloids versus crystalloids for fluid resuscitation in critically ill patients. Cochrane Database Syst Rev 2013;(2):CD000567. 